\title{
Determination of Mealiness in Apples using Ultrasonic Measurements
}

\author{
A. Bechar ${ }^{1}$; A. Mizrach ${ }^{1}$; P. Barreiro ${ }^{2}$ S. Landahl ${ }^{3}$ \\ 'Institute of Agricultural Engineering, A.R.O., The Volcani Center, P.O. Box 6, Bet Dagan, 50250, Israel; e-mail of corresponding author: \\ avital $(\alpha$ volcani.agri.gov.il \\ ${ }^{2}$ Universidad Politecnica de Madrid, Madrid, Spain; e-mail: pbarreiro@iru.etsia.upm.es \\ ${ }^{3}$ Katholieke Universiteit Leuven, Leuven, Belgium; e-mail; sandra.landahl $\omega$ agr.kuleuven.ac.be
}

\begin{abstract}
A system based on ultrasonic energy absorbance was developed, for non-destructive measurements of threc levels of texture degradation towards mealiness in Jonagold and Cox apples. The ultrasonic system comprises a high-power generator and a pair of $80 \mathrm{kHz}$ ultrasonic transducers. One transducer, acting as a transmitter, sends a pulse through the apple tissue, which absorbs part of its energy, depending on internal textural attributes, and the transmitted pulse is received as an emerging signal by the other transducer. The detected ultrasound waves were analysed in parallel with the determination of the mealiness level of the fruit in accordance with destructive measurements in confined compression. The results obtained in Cox apples showed a good correlation between the ultrasound measurements and the confined-compression destructive tests for each mealiness level.
\end{abstract}

\section{Introduction}

In apples, texture seems to be the predominant quality attribute, together with flavour and appearance (Lapsley et al., 1992). Crispness, firmness, hardness, juiciness and mealiness are the most generally recognised texture attributes in apples, and mealiness impairs the quality of apples and reduces their market value. Consumers are capable of distinguishing a mcaly product from a fresh one, identifying it correctly with terms such as non-juicy, soft, etc. Nevertheless, there is a need for a reliable method, supported by appropriate sensors, for the nondestructive measurement and classification of apples in terms of their mealiness; furthermore, such a method must be usable by an untrained person. The demand for high-quality calls for a reliable, rapid, non-destructive, non-invasive technique for measuring some of the texture attributes of the fruit, especially mealiness; these attributes develop as the fruit matures and are indicative of its quality. Several techniques for detection and measurement of mealiness have been suggested in the literature, in addition to sensory analysis. Destructive methods include texture profile analysis ( $\mathrm{Tu} \& \mathrm{De}$
Baerdemaeker, 1995), tensile tests (Tu et al., 1996), acoustic (Abbott et al., 1968) and ultrasonic wave propagation in slices of apple tissues (De Smedt, 2000); and non-destructive methods include magnetic resonance techniques (Barreiro et al., 1999), acoustic impulse response (Duprat et al., 1997); near infrared (NIR) (Lu \& Ariana, 2002); impact and NIR (Ortiz et al., 2001), and laser (Cho \& Han, 1999).

A system and method based on ultrasonic energy absorbance was suggested by Mizrach et al. (2003) for rapid non-destructive measurement of mealiness in apples. This method is based on a patented development, which enables the fruit quality attributes to be observed by measuring the changes in ultrasonic sound waves passing through the fruit tissue over a short distance across the peel (Mizrach et al., 1994).

The present paper suggests an analytical method for comparing the results obtained by an ultrasound technique with those of destructive determinations of mealiness level based on the destructive measurements of maximum force and hardness in confined compression, and on the juiciness of the apple tissue (Barreiro et al., 1998). 


\section{Materials and methods}

\subsection{Fruit selection}

Two apple varieties (Malus domestica Borkh L., cvs Jonagold and Cox) were selected, and 60 fruits of each cultivar were used. The fruits were picked at the fruit grower, Thielkens, in Belgium, and were treated at the Flanders Centre/Laboratory (in the Katholieke Universiteit in Leuven, Belgium) to enhance three different levels of ripening, by the application of a protocol that had been developed to produce mealy fruits (FAIR, 1998). The FAIR protocol involves subjecting the apples to various combinations of temperature, humidity and storage time. Three mealiness levels were achieved through appropriate treatments: fresh $\left[3{ }^{\circ} \mathrm{C}, 95 \%\right.$ relative humidity $(\mathrm{RH}), 26$ days], ripe $\left[3{ }^{\circ} \mathrm{C}, 95 \% \mathrm{RH}\right.$, 16 days followed by $20^{\circ} \mathrm{C}, 95 \% \mathrm{RH}, 10$ days], and overripe $\left[20^{\circ} \mathrm{C}, 95 \% \mathrm{RH}, 26\right.$ days].

There is a well-known relationship between the preparation protocol and the onset of mealiness. However, it is necessary to examine the various development stages of mealiness in fruits individually, as not all are equally affected by the mealinessenhancing process (FAIR protocol), therefore, the degree of mealiness at each stage was determined by a specific destructive test. Thus, the mealiness level was determined by destructive tests in confined compression (Barreiro et al., 1998).

\subsection{Principles and instrumentation of ultrasonic tests}

The ultrasonic system is based on the emission of known ultrasonic energy into the fruit flesh and measurement of the ultrasonic energy received after the passage of the signal through the fruit tissue and over a short distance across the peel. The mechanical structure of the tissue, its physiochemical quality indices, and each change in the quality attributes of the fruit, affect the energy of the received signal. Previous studies found a good correlation between the attenuation of the ultrasonic signal and the mechanical and physiological changes in the fruit tissue (Mizrach et al., 1994, 1996, 1997, 1999, 1999a, 1999b, 2000). It was found that there were linear correlations between the force applied and the energy absorbed in the tissue, and that the gradient of the linear correlation equation changed according to the structural and physiological changes in the fruit tissue (Mizrach et al., 1997). The present experimental arrangement included mechanical, electronic and microcomputer units (Fig. 1). The mechanical unit comprised a pair of $80 \mathrm{kHz}$ ultrasonic transducers assembled together and mounted with a

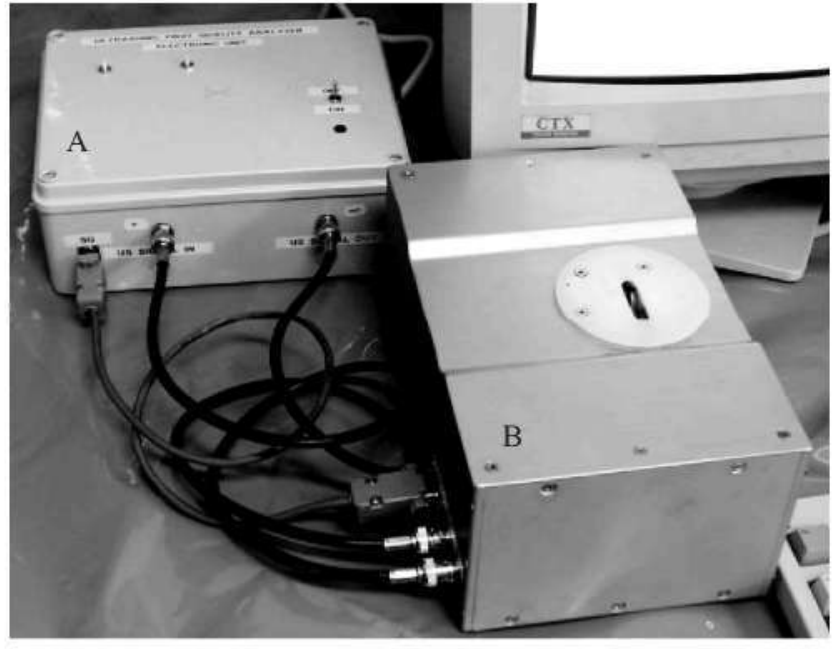

Fig 1. Ultrasonic experimental arrangement: box $A$, electronic unit; box B, mechanical unit

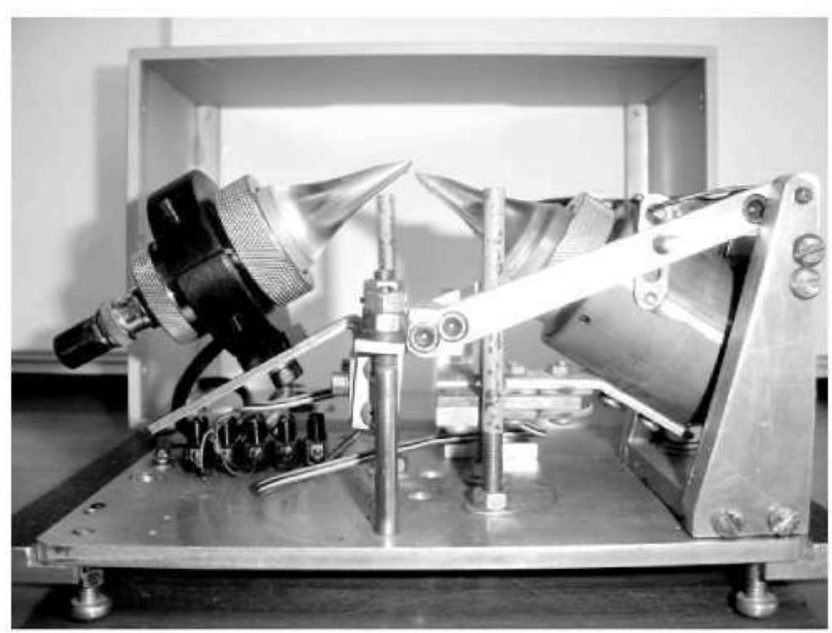

Fig 2. View of transducers and sensors assembly of the mechanical unit

known gap (about $2 \mathrm{~mm}$ ) and angle $\left(120^{\circ}\right)$ between their tips (Fig. 2). Exponential Plexiglas energy concentrators were used to match each transducer ( $35 \mathrm{~mm}$ in diameter) to a chisel-type contact end $(0.2 \mathrm{~mm}$ by $3 \mathrm{~mm})$ at the fruit surface. One transducer acted as a transmitter and the other as a receiver; the transmitted pulse passed through the apple tissue, covered about $5 \mathrm{~mm}$ in the vicinity between the tips, in which part of its energy was absorbed, depending on internal textural attributes, and the receiver collected the transmitted signal (Mizrach et al., 1994). The transmitter was attached to a straingage element that measured the force between the transducer and the fruit. The electronic unit comprised a high-power ultrasonic generator for activating and 


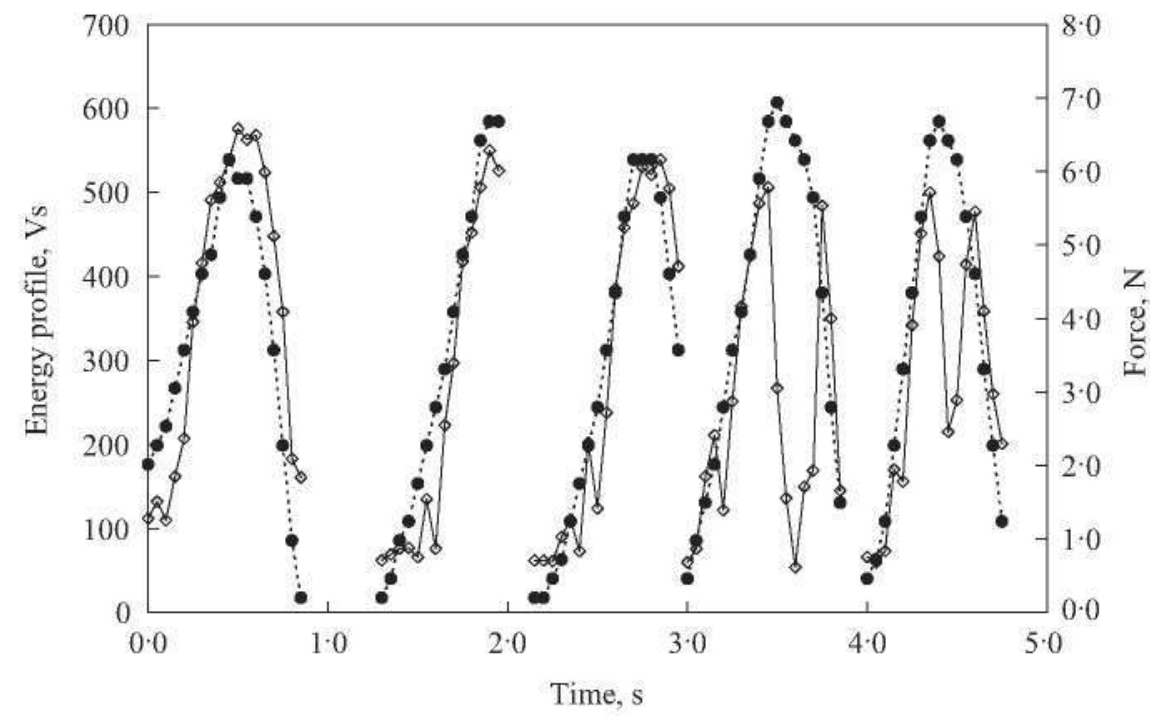

Fig 3. Force $(\cdots \bullet \cdots)$ and energy profile $(-\diamond-)$ Versus time in discrete measurements (sample shown for green Jonagold apple)

monitoring the transducers, a strain-gauge controller, and a microprocessor unit that collected and processed the ultrasonic signals and strain-gauge readings, and sent the output to an external data acquisition system for further analysis (Mizrach et al., 2003).

\subsection{Ultrasonic test procedures}

The ultrasonic measurements were performed on the red and on the green side of each fruit. The system was activated when a fruit was placed in contact with the transmitter and receiver tips, and a mechanical load was applied to them. Each fruit sample was tested under discrete manual loading increases (Fig. 3). The received ultrasonic energy and the mechanical loads applied to the fruit were measured simultaneously and recorded as series of data points at the rate of $20 \mathrm{~Hz}$. To ensure synchronisation in capturing of ultrasonic data with load readings, each fruit was subjected to four to six loading cycles, each lasting $1 \mathrm{~s}$, resulting in 20 data points per cycle with contact loads ranging from 0 to $9.53 \mathrm{~N}$. Only the first successfully synchronised measurement was considered as an appropriate data point.

\subsection{Principles and instrumentation of destructive tests in confined compression}

A confined compression test was carried out with a Chatillon LRX testing machine and cylindrical probes (Fig. 4). The confined cylinder measured $17 \mathrm{~mm}$ in length and $17 \mathrm{~mm}$ in diameter, the cylindrical fruit sample was extracted from the outer part of the fruit

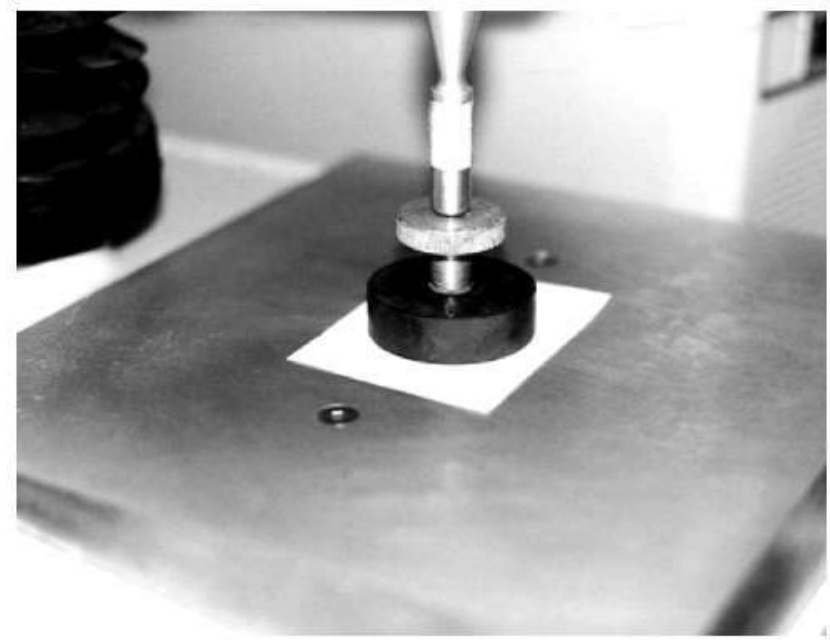

Fig. 4. A confined compression test device

tissue in the vicinity of the ultrasonic readings. The probes were confined in a hole of the same diameter as the fruit cylinder, in a disc of thickness equal to the probe height. Deformation was applied at $20 \mathrm{~mm} / \mathrm{min}$, to a maximum deformation of $2.5 \mathrm{~mm}$. A $15.3 \mathrm{~mm}$ diameter rod was used as the probe, in order to avoid contact between the rod and the disc during compression. When maximum deformation was reached, the machine relaxed the deforming compression at the same rate in the opposite direction. One such test was performed on each fruit. The following data were recorded: maximum force at $2.5 \mathrm{~mm}$ deformation; force to deformation ratio (compression hardness) within the 
elastic regime; and juiciness, as expressed by the area of the juice spot that spread on a filter paper placed beneath the confining cell during the test. The measured data were combined in a computed texture degradation scale, ranging from 0 to 11 in which $0-3$ was considered as fresh, 3-6 as ripe, and 6-11 as overripe (Barreiro et al., 1998).

\subsection{Data analysis}

A program was implemented in Matlab software (1995); it processed the ultrasonic energy records and the applied force data obtained by the discrete loading method for each fruit sample. The energy profile and force applied were correlated to yield linear equations for each apple, each side, and each cultivar. The gradient (slope) in each equation was designated as the calculated value of the mealiness of the sample. The average correlation was found to be $R^{2}=0.69$ for all fruits (Mizrach et al., 2003). The linear analysis between energy profile and force applied was described in details previously (Mizrach et al, 2003).

Data were subjected to analysis of variance (ANOVA), to multivariate analysis of variance (MANOVA), to Student's $t$-test, with level of significance $\alpha$ of 0.05 , and to linear discriminant analysis.

\section{Results and discussion}

According to the destructive tests in confined compression method, out of the 120 fruits (comprising 60 of each of the two cultivars), 88 fruits were considered as fresh, 22 as ripe, and 10 as overripe. The classification of mealiness, as determined by the destructive test, was designated as a reference for the degree of mealiness and was compared with the results of the ultrasonic measurements. Table 1 summarises the results of the ultrasonic measurements for Jonagold and Cox apples, as obtained from the samples.

Not all of the fruits prepared for this study were successfully measured with the ultrasonic device. Some of the fruits could not provide ultrasonic readings and therefore, the total number of fruits listed in the table is less than the initially prepared 120 .

In Jonagold apples, the average energy to force ratio (slope) for the green side was higher than that for the red side, for all mealiness groups. On the green side of the Jonagold apples, the values for overripe fruits were higher than those for fresh ones, whereas on the red side the values for fresh and overripe apples were alike. The results obtained for Jonagold apples did not correlate well with the mealiness levels; the differences were found to be minor and statistically insignificant, therefore, the results obtained for Jonagold apples by this method were not considered in the analysis.

In Cox apples, the slopes for fresh and ripe apples were alike, which implies that the resolution provided by ultrasonic measurements might be insufficient to distinguish between fresh and ripe fruits in terms of mealiness. Therefore, a comparison was made only between fresh and overripe mealiness groups.

Figntre 5 shows the average slopes on Cox apples. For the red side measurements, the average slope obtained with the overripe group was 1.88 times as steep as that of the fresh group, and the difference was statistically significant $(\alpha=0.05)$. For the green side measurements, the average slope obtained with the overripe group was $56 \%$ steeper than that of the fresh group but the difference between the groups was insignificant.

Table 1

Average results for energy to force ratio (slope), obtained from the measurements in Jonagold and Cox apples

\begin{tabular}{|c|c|c|c|c|c|c|c|}
\hline \multirow[b]{3}{*}{ Variety } & & \multicolumn{6}{|c|}{ Energy to force ratio, $V_{s} / N$} \\
\hline & & \multicolumn{3}{|c|}{ Green } & \multicolumn{3}{|c|}{ Red } \\
\hline & & Fresh & Ripe & Overripe & Fresh & Ripe & Overripe \\
\hline Jonagold & $\begin{array}{l}n^{\mathrm{a}} \\
\text { Av. } \\
\text { S.D. }\end{array}$ & $\begin{array}{r}27 \\
18.95 \\
13.52\end{array}$ & $\begin{array}{r}8 \\
22.48 \\
18 \cdot 16\end{array}$ & $\begin{array}{r}4 \\
25 \cdot 32 \\
13 \cdot 36\end{array}$ & $\begin{array}{r}30 \\
14.22 \\
9.58\end{array}$ & $\begin{array}{r}8 \\
20 \cdot 92 \\
18 \cdot 59\end{array}$ & $\begin{array}{r}4 \\
12.77 \\
8.92\end{array}$ \\
\hline $\operatorname{Cox}$ & $\begin{array}{l}n^{\mathrm{a}} \\
\text { Av. } \\
\text { S.D. }\end{array}$ & $\begin{array}{r}29 \\
17.21 \\
10.54\end{array}$ & $\begin{array}{r}6 \\
17.01 \\
5.43\end{array}$ & $\begin{array}{r}4 \\
26 \cdot 79 \\
18 \cdot 80\end{array}$ & $\begin{array}{r}25 \\
20.95 \\
13.54\end{array}$ & $\begin{array}{r}8 \\
18+82 \\
15+42\end{array}$ & $\begin{array}{r}3 \\
39.50 \\
14.05\end{array}$ \\
\hline
\end{tabular}

an, nuber of fruits.

${ }^{b} S . D$. sfandard deviation. 


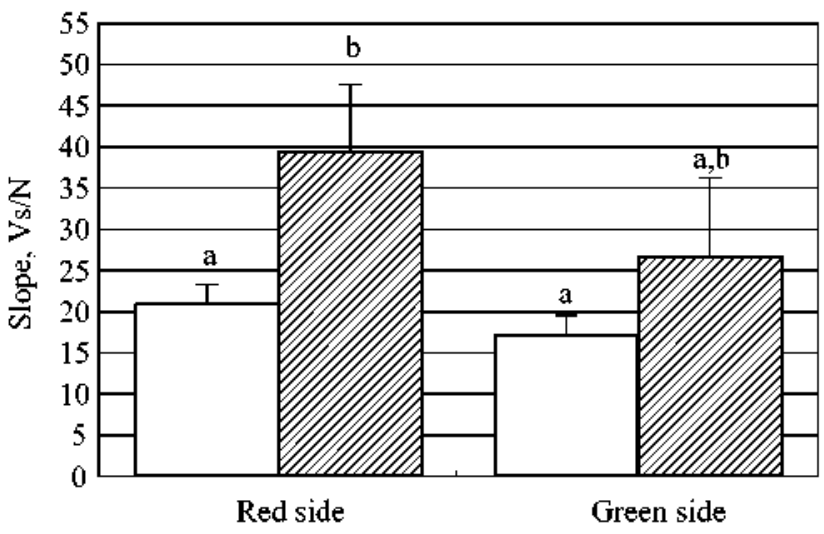

Fig 5. Average slopes on the red and green sides for different mealiness levels, as determined by the destructive rests in Cox apple; the different letters represent $95 \%$ significance of difference; the error bars represent the standard error: il, fresh; $\ldots$, overripe

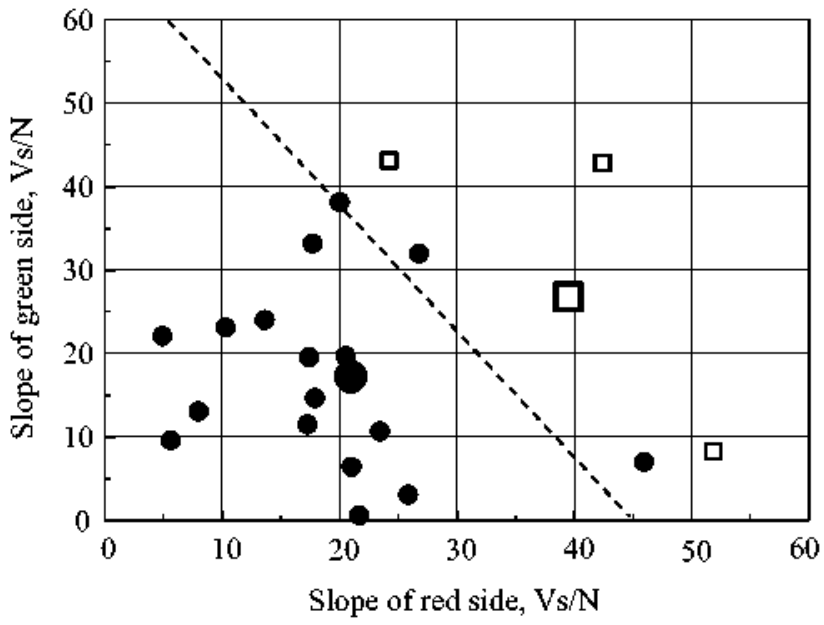

Fig 6. Red-green coordination system for Cox apples: $\bullet$ fresh apples; - average of the fresh uroup; $\square$, overripe apples; $\square$. average of the ripe group; ----, decision boundary line between the fresh and overripe apples based on the linear discriminam analysis

In order to classify the mealiness level of each individual fruit, 20 apples that were successfully measured on both, red and green sides for the same fruit were taken. Multivariate analysis of variance (MANOVA) was performed on the red and green side parameters. It was found that the difference between the fresh and overripe groups that were classified by the confined-compression tests was statistically significant $(\alpha=0.05)$. In addition, the significant difference between the mealiness groups, revealed good matching between the classifications, determined by the ultrasonic measurements and the confined-compression tests.
Figure 6 presents the results obtained from the classified Cox apples in a red-green coordination system i.e. red-side slope values plotted against green-side slope values.

The fresh apples are located in the lower left area of the graph, and the overripe apples are in the upper and right areas, where at least one coordinate value is high. The distance (vector magnitude) between the origin of axes to the average point of the overripe group is higher by $76 \%$ than of the fresh group. A linear discriminant analysis was performed on the results, revealed that the misclassification error rate was $5.8 \%$ and that the decision boundary equation between the fresh and overripe groups in Fig. 6 found to be:

$$
y=-1.55 x+69.3
$$

where $x$ and $y$ are the slopes of the red-side and greenside, respectively, in $V_{s} / N$.

\section{Conclusions}

A system based on ultrasonic energy absorption technique was evaluated as a possible means for rapid non-destructive measurement of mealiness in intact apples. Ultrasonic energy transmitted through the fruit tissue and the load applied on the transducers was simultaneously measured. Linear equations were calculated between the ultrasonic energy and the load applied for each colour side of each apple. The slope of the linear plot of each equation was extracted as a measure of the mealiness of the sample.

The comparison between the results of the ultrasound measurements and the confined-compression tests showed good matching (probability $\alpha=0.05$ ) with the slopes for the fresh and the overripe mealiness levels for Cox apples (e.g. for measurements on the red side, the average slope for overripe fruits was higher by $88 \%$ than that for fresh fruits). The ultrasound results obtained for Jonagold apples did not correlate well with the mealiness levels; the differences were found to be minor and statistically insignificant.

\section{Acknowledgments}

The financial support of the Commission of the European Communities is gratefully acknowledged (Concerted Action 'ASTEQ-Artificial Sensing Techniques for Evaluating Quality' FAIR5 CT97-3516). The contents of this publication are the sole responsibility of the authors and in no way represent the views of the Commission or its services. 
Contribution from the Institute of Agricultural Engineering, the Agricultural Research Organization, the Volcani Center, Bet Dagan, Israel, No. 704/04 series.

\section{References}

Abbott J A; Bachman G S; Childers $\mathbf{N}$ F; Fitzgerald J V; Matusik F J (1968). Sonics techniques for measuring texture of fruits and vegetables. Food Technology, 22(5), 101-112

Barreiro P; Cabello J; Fernandez-Valle M E; Ortiz C; RuizAltisent $\mathbf{M}$ (1999). Mealiness assessment in apples using MRI techniques. Magnetic Resonance Imaging. 17(2), 275-281

Barreiro P; Ortiz C; Ruiz-Altisent M; De Smedt V; Schotte S; Andani Z; Wakeling I; Beyts P K (1998). Comparison between sensory and instrumental measurements for mealiness assessment in apples. A collaborative test. Journal of Texture Studies, 29(5), 509-525

Cho Y J; Han Y J (1999). Nondestructive characterization of apple firmness by quantitation of laser scatter. Journal of Texture Studies, 30, 625-638

De Smedt V (2000). Measurement and modeling of mealiness in apples. $\mathrm{PhD}$ Thesis, Katholieke University of Leuven. Belgium

Duprat F; Grotte M; Pietri E; Loonis D (1997). The acoustic impulse response method for measuring the overall firmness of fruit. Journal of Agricultural Engineering Research, 66(4), 251-259

FAIR (1998). Mealiness in fruits. Consumer perception and means for detection. Contract No. FAIR-CT95-0302, 4th Framework Program, European Commission. DirectorateGeneral XII. B-1049 Brussels.

Lapsley G K; Escher F E; Hoehn E (1992). The cellular structure of selected apple varieties. Food Structure, 11, 339-349

Lu R; Ariana D (2002). A near-infrared sensing technique for measuring internal quality of apple fruit. Applied Engineering in Agriculture, 18(5). 585-590

Matlab (1995). Matlab Software, version 5.3. Matliworks Inc, South Natick. MA
Mizrach A; Bechar A; Grinshpon Y; Hofman A; Egozi H; Rosenfeld L (2003). Ultrasonic mealiness classification of apples. Transactions of the ASAE, 46(2). 397-400

Mizrach A; Flitsanoy U (1999). Nondestructive ultrasonic determination of avocado softening process. Journal of Food Engineering, 40, 139-144

Mizrach A; Flitsanov U; Akerman M; Zauberman G (2000). Monitoring avocado softening in low-temperature storage using ultrasonic measurements. Computers and Electronics in Agriculture, 26, 199-207

Mizrach A; Flitsanov U; EJ-Batsri R; Degani H (1999a). Determination of avocado maturity by ultrasonic attenuation measurements. Scientia Horticulturae, 80, 173-180

Mizrach A; Flitsanov U; Fuchs Y (1997). An ultrasonic nondestructive method for measuring maturity of mango fruit. Transactions of the ASAE. 40, 1107-1111

Mizrach A; Flitsanov U; Schmilovitch Z; Fuchs Y (1999b). Determination of mango physiological indices by mechanical wave analysis. Postharvest Biology and Technology, 16, $179-186$

Mizrach A; Galili N; Gan-mor S; Flitsanoy U; Prigozin I (1996). Models of ultrasonic parameters to assess avocado properties and shelf life. Joumal of Agricultural Engineering Research, 65, 261-267

Mizrach A; Galili N; Rosenhouse G (1994). Method and a system for non-destructive determination of quality parameters in fresh produce. Israel Patent No. 109406; USA Patent No. 5,589,209; French Patent No. 9504869

Ortiz C; Barreiro P; Correra E; Riquelme F; Ruiz-Altisent M (2001). Non-destructive identification of woolly peaches using impact response and near infrared spectroscopy. Joumal of Agricultural Engineering Research, 78, 281-289

Tu K; De Baerdemaeker J (1995). Investigate apple mealy texture using instrumental methods. Agri-Food Quality, 204-207

Tu K; De Baerdemaeker J; Deltour R; deBarsy T (1996). Monitoring post-harvest quality of Granny Smith apple under simulated shelf-life conditions: destructive, nondestructive and analytical measurements. International Joumal of Food Science and Technology, 31(3), 267-276 